Article

\title{
Sustainability Education and Environmental Worldviews: Shifting a Paradigm
}

\author{
Simon Ling ${ }^{1, *}$, Adam Landon ${ }^{2}$, Michael Tarrant ${ }^{1}$ and Donald Rubin ${ }^{3}(\mathbb{C}$ \\ 1 Warnell School of Forestry and Natural Resources, University of Georgia, Athens, GA 30602, USA; \\ tarrant@uga.edu \\ 2 Department of Fisheries, Wildlife, and Conservation Biology, University of Minnesota, \\ Minneapolis, MN 55455, USA; alandon@umn.edu \\ 3 Franklin College of Arts and Sciences, University of Georgia, Athens, GA 30602, USA; drubin@uga.edu \\ * Correspondence: stl22004@uga.edu
}

Received: 9 September 2020; Accepted: 2 October 2020; Published: 7 October 2020

check for updates

\begin{abstract}
Higher education institutions are tasked with education for sustainable development, of which the environment is a central pillar. Understanding the demographic factors that influence the establishment of environmental worldviews allows educators to better contextualize sustainability content and discussion. Identifying pedagogies capable of creating learning spaces within which worldviews can shift offers similar opportunities. Using a quasi-experimental design and model building, this study identifies important social psychological antecedents of environmental beliefs, assesses the effectiveness of outbound mobility pedagogy at changing those beliefs and identifies important predictors of the nature and magnitude of those changes. Sustainable outbound mobility courses were effective at increasing environmental worldview compared to a control group. At program commencement, political orientation and business majors were negatively associated with environmental worldview, while female gender was the reverse. For sustainability education courses, only gender was retained as a significant predictor of the nature and change of environmental worldview by the course's end. These results suggest that the factors associated with environmental worldview upon commencement of a course do not necessarily predict the malleability of that worldview in higher education students.
\end{abstract}

Keywords: sustainability education; environmental worldview; new ecological paradigm; outbound mobility; quasi-experimental

\section{Introduction}

Universities in the U.S. recognize the benefits of study abroad and its potential for experiential learning and for nurturing undergraduates with global experience and perspectives. Over 341,000 U.S. students studied abroad for academic credit over the course of the 2018/2019 academic year [1]. Study abroad has been put forward as a potentially transformative experience for participants [2-4] with the ability to alter participants' beliefs, attitudes and behaviors regarding sustainability and the triple bottom line of society, economics and the environment [5].

As one of the pillars of modern sustainability concepts, the environment is an integral component of sustainability education content. Therefore, the factors that influence the environmental worldview of students are of interest in the design of sustainability communication and education approaches. Knowledge thereof gives educators the ability to focus on content relevant to students. Knowledge of the socio-demographic factors influencing change in student environmental worldviews in response to programs designed to do so should also inform more effective curriculum design. 
Thus, the identification of effective teaching practices and/or learning experiences has the potential to increase the effectiveness of sustainability education efforts within higher education institutions.

The New Ecological Paradigm has emerged as one of the leading measures used to tap into environmental beliefs since its introduction in 1978 (as the New Environmental Paradigm) and subsequent revision in 2000 [6]. It has become an important component of testing approaches investigating how pro-environmental attitudes evolve and how they are related to behavior through value-belief norm theory and the theory of planned behavior $[7,8]$.

Using the New Ecological Paradigm as a measure of environmental worldview, this study first examines the demographic traits that influence students' positions on its spectrum at the commencement of a higher education course. Second, changes in environmental worldview on sustainable educational travel of students versus a control group is tested. Finally, socio-demographic traits related to the magnitude and/or direction of change in student environmental worldviews are identified. The results of this work identify factors influential in the formation and evolution of students' environmental values with the aim of improving the design of pedagogical approaches aiming to foster critical examination and self-reflection of environmental worldviews.

\subsection{New Ecological Paradigm}

The New Ecological Paradigm [9] evolved from its predecessor the New Environmental Paradigm [10] and has arguably become the most widely applied and evaluated measure used to assess and track changes in environmental worldview since its implementation [6,11]. Grounded in Rokeach's theory of values [12], the New Ecological Paradigm was assessed for internal consistency, dimensionality and validity on its inception [9] and has been constantly tested, and tinkered with, around the world. In 2018, Google Scholar listed 4384 citations since its publication [13].

The NEP (New Ecological Paradigm) measures the degree to which individuals express adherence to eco-centric worldviews, at one end of the spectrum, and anthropocentric worldviews at the other. Dunlap et al. [9] conceptualize the NEP as examining five "facets":

1. Reality of limits to growth.

2. Anti-anthropocentrism.

3. Fragility of nature.

4. Rejection of exemptionalism.

5. Possibility of eco-crises or ecological catastrophe.

Respondents with higher NEP scores identify more closely with concepts that see humans as part of natural systems. Respondents with lower scores identify more closely with concepts that place humans apart from, or above, natural systems [10].

\subsection{Criticisms of the NEP}

Critiques of the NEP can be broadly grouped into three categories [11,14]. First, that the NEP lacks important theoretical elements of a pro-ecological worldview $[15,16]$. Lundmark [16] points out that in relation to the "limits to growth" facet, the NEP fails to incorporate the social and economic aspects of the contemporary sustainability debate. Furthermore, Lundmark [16] points out that it is humanity's exceptional abilities that allow us to perceive the dominant social paradigm as unsustainable, suggesting that the simple antagonistic relationship between anthropocentrism and ecocentrism posited by the NEP may not be sufficient.

The second major criticism of the NEP is that it does not relate strongly to pro-environmental behavior [6]. Given that the measure was never intended to measure behaviors, this criticism has gained little traction within the literature. The NEP may detect changes in the attitudes and motives underlying pro-environmental behavior, but not necessarily the ability to act upon them $[6,8]$. Using a measure for a purpose for which it was never designed renders it invalid before the first respondent puts pen to paper [17]. 
A third major criticism of the measure, and the issue that has been raised most often, is that the NEP is not consistently unidimensional. Researchers have found anywhere from one to five factors underlying the NEP, which calls into question Dunlap et al.'s assertion of unidimensionality $[14,18,19]$.

However, the analytic approaches used to criticize the NEP's dimensionality are fundamentally sample dependent, residing within the realm of the scoring tradition of psychometric measurement theory [20]. Thus, inconsistency in dimensionality should be expected, at least to some degree, when the measure is deployed in a novel population. Dunlap himself recognizes this and has consistently recommended the NEP's dimensionality be investigated by factor analysis with each deployment to contextualize findings and facilitate comparison [6].

Hawcroft and Milfont's [14] comprehensive review and meta-analysis makes some valid criticism about the inconsistency with which the NEP has been deployed and reported, noting drawbacks in edited versions of the NEP in which substantial numbers of items have sometimes been omitted. Furthermore, they draw attention to the inconsistency in reporting basic statistical and demographic information for the NEP and the sample within which it is being deployed. Perhaps most importantly, Hawcroft and Milfont report numerous studies that fail to either investigate or report the internal consistency of the NEP scale within their sample.

\subsection{Demographic Antecedents to the NEP}

Demographic factors are known to influence environmental attitudes and beliefs. Early work in this area found age or birth cohort to be a strong, consistent predictor of environmentalism [21,22]. More specifically, several demographic variables are known to be associated with the NEP. Dunlap et al. [9] found political liberalism to be strongly correlated with higher NEP $(\mathrm{r}=0.32$, $p<0.05)$, with other variables significant at the same level including age $(\mathrm{r}=-0.11)$, education $(\mathrm{r}=0.10)$, political party $(r=0.22$; Democrats scoring higher) and occupational sector $(r=0.13$; primary industry workers score lower).

Using the 2000 National Survey on Recreation and the Environment, Johnson, et al. [23] found significant relationships to NEP scores at $\alpha=0.05$ for ethnicity (variable, depending on ethnicity), gender (higher in females), age (negative relationship), family size (negative relationship) and political orientation (higher in liberals). Casey and Scott [24] also found gender, level of education and age influential on NEP scores in an Australian study drawing samples from 126 urban and rural locations using the same level of significance. More recently, Rexeisen [25] and Rexeisen and Al-Khatib [26] report gender as a significant moderator of change in NEP scores over time.

Dunlap and colleagues make no mention of gender in the NEP founding paper [9]. However, gender has been long known as influential on environmental concern and attitudes within the broader literature and the literature specific to the NEP, although its influence is reported by some as weaker and less consistent than that of age or birth cohort [27-29].

\subsection{The NEP in a Social Psychological Context}

Conceptually, the NEP has been examined within the framework of the value-belief-norm theory of pro-environmental behavior (VBN), which in turn is based on the norm-activation model (NAM) of Schwartz [30], as well as in explorations of the theory of planned behavior (TPB) [31,32]. Stern et al. $[29,33]$ see the NEP as measuring grass-roots environmental beliefs, which are less intransigent than norms, but more intransigent than values. In turn, values are underpinned by an individual's position in their social structure, their institutional constraints and their incentive structure. In this scheme, an individual's social setting frames their values, which then frame general beliefs and worldview, such as the NEP.

The NEP is conceptualized as dependent on the balance of personal values spread between three themes (altruistic, biospheric and egoistic) and has been utilized to model multiple outcomes, such as pro-environmental behavior/intention (Figure 1) [5,8] and citizenship types [34]. Generally, the NEP is 
associated positively with biospheric values and negatively with egoistic values, and its relationship with altruistic variables is indistinct $[35,36]$.

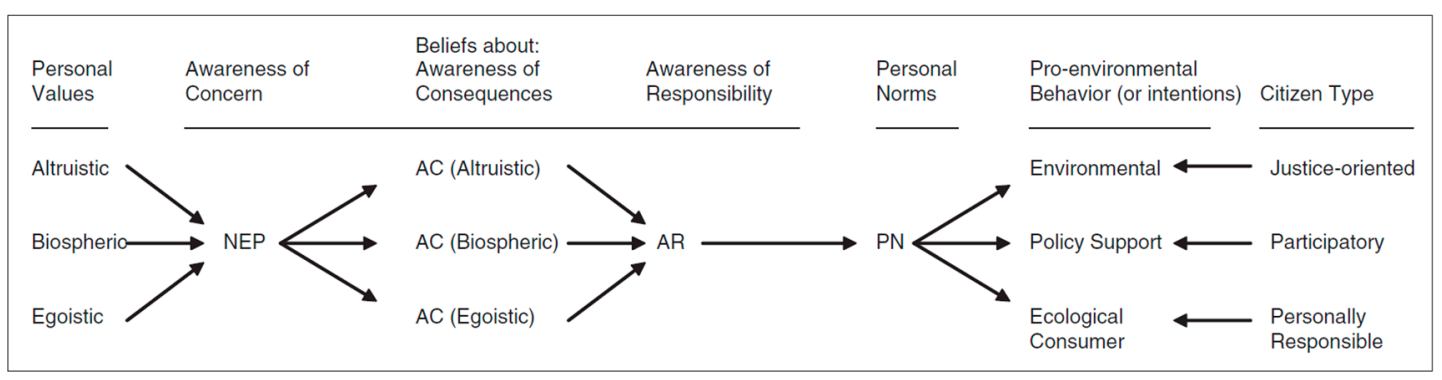

Figure 1. Adapted value-belief-norm theory of global citizenship from [5].

\subsection{Outbound Mobility and the NEP}

Outbound mobility can be based upon several significant theories of learning. Experiential learning theory (ELT) [37], whereby individuals construct meaning by reflecting on learning experiences of any kind, is well suited to the variability in learning experiences offered by educational travel and its mix of formal, informal, physical and intellectual learning opportunities.

Transformational learning theory (TLT) [38] follows on from ELT in that critical reflection is a core component. Building on critical reflection as core, TLT argues that changes in learners' perspectives occur through shifts in mental models that also increase an individual's investment in their own knowledge and learning experiences $[38,39]$. This is a critical concept for sustainability educational programs seeking to foster changes in attitudes, behaviors, or perspectives that are constructed upon deeply held values and/or beliefs. International education has demonstrated the potential to facilitate shifts in values, beliefs and scope of worldview in line with TLT [34,40].

Situational learning theory (SLT) [41] insists that the reflective practice, central to the construction of meaning in ELT, cannot be considered in isolation from the physical, mental and cultural world in which it occurs [42]. From this perspective, meaning is not constructed in abstraction from the learner as a biological entity embedded in a physical world contextualized by culture.

Critical cultural pedagogy prioritizes political context as central to cognition in the study of human learning processes $[43,44]$. Hierarchies of gender, race and wealth are among the political contexts focused upon in CCP (critical cultural pedagogy). Learners are asked to critically examine socio-political contexts within themselves and for others in order to foster learners' abilities to be more discriminating as to how they invest themselves in the hierarchies at hand [42].

Given the potential of these pedagogies to affect complex learning outcomes, it is somewhat surprising that while the NEP has been used to assess worldview in general higher education students [45], few projects have utilized the NEP to examine the effect of study abroad upon it. Fewer still have used quasi-experimental designs to facilitate comparative analysis of shifts in NEP scores between different course types.

Rexeisen [25] is among only a few authors to have used the NEP longitudinally in a study abroad context, deploying it to detect changes in business students studying abroad in London, surveying prior to departure, at the end of the semester abroad and four months after repatriation. He found support for a positive impact of study abroad on NEP scores over the course of the semester. Furthermore, when examining change over each of the five "facets" posited by Dunlap et al. [9], Rexeisen [25] found mixed results examining change after repatriation, with unexpected gains and losses in subscale scores. Previously, Rexeisen and Al-Khatib [26] found only limited support for study abroad influencing environmental attitudes with the only significant shift occurring on the exemptionalism subscale of the NEP. 


\section{Purpose and Hypotheses}

This study first seeks to identify the demographic antecedents to environmental worldview in higher education students. Second, it investigates the effects of different higher education pedagogies on environmental worldview across academic programs of between a few weeks and a semester in duration. Third, it examines what factors are significant predictors of the nature of any detected change in environmental worldview in the second step. Overall, the study intends to increase educators' understanding of the socio-political contexts within which environmental worldviews are generated, that they may better contextualize sustainability content and discussion and further understand the educational contexts within which environmental worldview may be moderated. We hypothesize that:

Hypotheses 1 (H1). Demographic factors are related to the magnitude of student's NEP scores at pretest in the following manner.

Hypothesis 1a (H1a). Females are associated with higher NEP scores.

Hypothesis $\mathbf{1 b}$ (H1b). Liberal political beliefs are associated with higher NEP scores.

Hypothesis 1c (H1c). Business majors are associated with lower NEP scores.

Hypothesis 1d (H1d). Class standing is positively associated with higher NEP scores.

Hypothesis 1e (H1e). Number of sustainability-related courses is positively associated with higher NEP scores.

Hypothesis 2 (H2). Sustainability educational/outbound mobility programs are associated with greater gains in NEP score pretest to posttest in comparison to other types of study abroad and home campus courses within the same time period, irrespective of course content.

Hypothesis 3 (H3). Demographic factors are related to the magnitude of change in student's NEP scores from pretest to posttest in Sustainability Educational/outbound mobility programs.

\section{Materials and Methods}

\subsection{Data Collection and Sample Demographics}

The study was conducted at a large public university in the southeastern United States of America. Data were drawn from a metadataset (MDS) generated from matched surveys completed on the first and last day of participating courses between 2008 and 2018. Surveyed students took courses on home campus, on residential campus study abroad programs or on outbound mobility programs. Home campus was defined as the campus at which a student was registered. Residential campus study abroad programs were defined as those where students were outside the U.S. and attending a foreign higher education institution where courses were delivered in a traditional classroom setting. Outbound mobility programs were defined as those where students were outside the U.S. and undertaking higher education classes delivered predominantly in the field rather than in classrooms. Not all measures deployed by the surveys were utilized every year.

For the purposes of this study, students were classified into two subcategories within the MDS; those that responded while undertaking outbound mobility programs were grouped into Sustainable Educational Travel sensu stricto programs (SETss) and those that responded while participating in home campus or residential campus study abroad programs were grouped into Other Programs (OP). Furthermore, when analyses were comparing SETss and OP subjects, data from years where measures yielded data for both categories were employed (2013-2018). Demographic features for each sample are presented in Table 1. 
Table 1. Sample socio-demographic breakdown.

\begin{tabular}{|c|c|c|c|c|c|c|c|c|c|}
\hline & $\mathbf{N}$ & $\begin{array}{c}\% \\
\text { Female }\end{array}$ & $\begin{array}{c}\% \\
\text { Freshman }\end{array}$ & $\begin{array}{c}\% \\
\text { Sophomore }\end{array}$ & $\begin{array}{c}\% \\
\text { Junior }\end{array}$ & $\begin{array}{c}\% \\
\text { Senior }\end{array}$ & $\begin{array}{c}\% \\
\text { Graduate }\end{array}$ & $\begin{array}{c}\% \\
\text { Business } \\
\text { Major }\end{array}$ & $\begin{array}{c}\% \\
\text { Politically } \\
\text { Right }\end{array}$ \\
\hline MDS & 3607 & 68.7 & 8.2 & 27.3 & 35.3 & 25.6 & 3.1 & 20.1 & 60.1 \\
\hline SETss & 2622 & 70.1 & 8.4 & 29.9 & 34.8 & 24.3 & 2.6 & 23.1 & 62.4 \\
\hline 2013-18 SETss & 1775 & 71.5 & 10.8 & 34.2 & 34.6 & 18.2 & 2.3 & 21.0 & 66.0 \\
\hline 2013-18 OP & 1027 & 64.9 & 7.6 & 20.3 & 37.8 & 29.9 & 4.5 & 11.6 & 54.1 \\
\hline
\end{tabular}

Note: MDS = metadataset. SETss = Sustainable Educational Travel sensu stricto. OP = Other Programs. Percentages exclude invalid responses.

\subsection{Measures}

The New Ecological Paradigm scale [9] was used to measure worldview. In line with Dunlap et al.'s [9] findings, the scale was treated as unidimensional providing Cronbach's alpha was found to be sufficient.

Students were presented with 15 items, 8 worded positively and 7 negatively, representing beliefs about the relationship between humans and their environment. Reverse coding was employed on negatively worded items prior to summation of the final NEP score. Higher scores reflect a more biocentric worldview (humans are a part of natural systems) and lower scores reflect a more anthropocentric worldview (humans are above nature). A five-point Likert scale was employed to measure item responses where $1=$ strongly disagree, $5=$ strongly agree and $3=$ neither agree nor disagree.

Known correlates of the NEP were utilized to check its concurrent validity. Three personal value dimensions (Altruistic, Biospheric and Egoistic) [35] and the Environmental Citizenship scale [46] were correlated with the NEP scale.

Political orientation was assessed in two ways between 2008 and 2017; originally on a four-item scale, with no neutral point, and later a 7-item scale that included a neutral point. For this study, these responses were recategorized as either left-wing or right-wing. Subjects who indicated no affiliation on the later 7-item scale were omitted from analyses. Dummy coding for political orientation was 0 and 1 for left-wing and right-wing, respectively.

A gender variable was generated from a self-reported dichotomous item as male or female, dummy coded as 0 and 1 , respectively. Major of study was reduced to a dichotomous variable representing majors either outside or inside the school of business, dummy coded as 0 and 1 , respectively. Class standing, i.e., first year, second year ... graduate student, was coded 1 through 5.

To alleviate yearly cohort effects, raw NEP scores were converted to z-scores by year. This was done by year for SETsS and OP collectively for years where data existed for both groups and across all years for SETss subjects. The conversion was accomplished by calculating a subject's distance from the mean NEP score for the year in which they studied and converting it to units of standard deviations (for that year's sample distribution). The directionality of distance from the mean was preserved.

NEP change scores were converted to z-scores within SETss subjects. Mean change in NEP and the standard deviation for the sample distribution was calculated for each year. Each subject's change score was then converted into a distance from yearly mean change in NEP, retaining directionality, in units of yearly standard deviation.

The MDS was examined for outliers (greater than 4 standard deviations above or below the mean) and influential data with regards to paired NEP scores $(n=2502)$. Only one outlier, a respondent more than 4 standard deviations below the mean NEP score at pretest and more than 6.5 standard deviations above the mean change in NEP score pretest to posttest, was removed from the sample, leaving a sample of $n=2501$. 


\subsection{Analysis}

Analyses were conducted using the statistical software SPSS version 25.0 [47]. Prior to hypothesis testing, the reliability of the scale was assessed for the entire sample at pretest and posttest, as well as for each of the subsamples (SETss and OP) at both points. Demographic variables known from the literature to have some relationship to NEP scores (as above) were subjected to stepwise regression $(\alpha$ enter $=0.05, \alpha$ remove $=0.10)$ to determine if any were significant contributors to variation in NEP z-scores at pretest. This was conducted for the entire metadataset and for the SETss subgroup.

Validation of Sustainable Educational Travel as an effective treatment for increasing NEP scores was conducted using a repeated measures ANOVA of Time (pretest and posttest) by Treatment (SET and OP) for years where NEP data for both SET and OP groups were present. For those years when NEP scores were obtained only for SETss students, differences in mean NEP score pretest to posttest across all SETss data were analyzed using a paired $\mathrm{t}$-test.

Stepwise regression $(\alpha$ enter $=0.05, \alpha$ remove $=0.10$ ) of socio-demographic variables was used to identify significant predictors of change scores in NEP pretest to posttest in SETss students, using the change in NEP z-scores generated per the process outlined above.

\section{Results}

Summary statistics for the NEP at pretest and posttest are presented in Table 2. The increase in variation within the samples from pretest to posttest is of interest in contextualizing subsequent results and discussion thereof.

Table 2. Summary statistics for the New Ecological Paradigm.

\begin{tabular}{cccccc}
\hline & $\mathbf{n}$ & Minimum & Maximum & Mean & Standard Deviation \\
\hline MDS NEP Pretest & 3607 & 26 & 75 & 52.19 & 6.839 \\
MDS NEP Posttest & 3579 & 22 & 75 & 52.79 & 7.541 \\
2013-18 NEP Pretest & 2688 & 26 & 75 & 52.17 & 6.919 \\
2013-18 NEP Posttest & 2671 & 22 & 75 & 52.68 & 7.623 \\
\hline
\end{tabular}

Note: MDS = metadataset. 2013-18 are years where data for both Sustainable Educational Travel and Other Programs exist.

\subsection{Validation of the NEP within the Sample}

Principal components analysis for the NEP scale at pretest for the MDS yielded three factors with initial eigenvalues above 1.00, with the first factor explaining $27.23 \%$ of the variance in the sample. After varimax rotation, eight items loaded most heavily onto the first factor, five onto the second factor and the remaining two onto the third factor (Table 3). As Table 4 shows, these results are not dramatically dissimilar to Dunlap et al.'s [9] findings. However, this does not detract from the standing criticism that the NEP should not be considered unidimensional according to these (and many other) results. The item-factor structure did not change markedly for the NEP scale at posttest.

In the MDS, the NEP at pretest had corrected item-total correlations ranging from 0.13 to 0.56 with an average of 0.37. Three items had corrected item-total correlations lower than 0.30 (items 4, 6 and 14; Table 3). Removal of items 4 and 6 increased the coefficient alpha by 0.007 and 0.009 , respectively. Removal of item 14 did not affect coefficient alpha at this resolution. These changes were inconsequential to the point that the improvement gained by their removal is not worth the loss of comparability with other research using the NEP and they were retained for this purpose.

Reliability analysis of the NEP at pretest for the MDS yielded a coefficient $\alpha$ of 0.77 at pretest $(\mathrm{n}=3607)$ and 0.81 at posttest $(\mathrm{n}=3579)$ for both categories combined. Reliability of the NEP for the SETss group yielded 0.76 at pretest $(n=2622)$ and 0.81 posttest $(n=2619)$. The remainder of the sample (OP group) yielded 0.78 at pretest $(n=985)$ and 0.82 at posttest $(n=970)$ for coefficient $\alpha$. 
Table 3. Metadataset NEP (New Ecological Paradigm) pretest exploratory factor analysis (principal components with varimax rotation).

\begin{tabular}{|c|c|c|c|c|}
\hline & & Factor & & CITC * $^{*}$ \\
\hline Item Number & 1 & 2 & 3 & \\
\hline $\begin{array}{l}\text { 1. We are approaching the limit of the number of people the } \\
\text { earth can support. }\end{array}$ & 0.72 & -0.16 & 0.11 & 0.46 \\
\hline $\begin{array}{l}\text { 2. Humans have the right to modify the natural environment to } \\
\text { suit their needs. }\end{array}$ & 0.04 & 0.37 & 0.64 & 0.31 \\
\hline $\begin{array}{l}\text { 3. When humans interfere with nature it often produces } \\
\text { disastrous consequences. }\end{array}$ & 0.65 & 0.08 & -0.08 & 0.41 \\
\hline $\begin{array}{l}\text { 4. Human ingenuity will ensure that we do NOT make the earth } \\
\text { unlivable. }\end{array}$ & 0.15 & 0.60 & 0.21 & 0.14 \\
\hline 5. Humans are severely abusing the environment. & 0.74 & 0.01 & -0.14 & 0.53 \\
\hline $\begin{array}{l}\text { 6. The earth has plenty of natural resources if we just learn how } \\
\text { to develop them. }\end{array}$ & 0.07 & 0.70 & -0.02 & 0.13 \\
\hline 7. Plants and animals have as much right as humans to exist. & 0.56 & 0.30 & -0.49 & 0.43 \\
\hline $\begin{array}{l}\text { 8. The balance of nature is strong enough to cope with the } \\
\text { impacts of modern industrial nations. }\end{array}$ & -0.14 & 0.66 & 0.19 & 0.34 \\
\hline $\begin{array}{l}\text { 9. Despite our special abilities humans are still subject to the } \\
\text { laws of nature. }\end{array}$ & 0.60 & 0.29 & -0.16 & 0.33 \\
\hline $\begin{array}{l}\text { 10. The so-called "ecological crisis" facing humankind has been } \\
\text { greatly exaggerated. }\end{array}$ & -0.20 & 0.49 & 0.47 & 0.44 \\
\hline $\begin{array}{c}\text { 11. The earth is like a spaceship with very limited room } \\
\text { and resources. }\end{array}$ & 0.72 & -0.18 & 0.16 & 0.45 \\
\hline 12. Humans were meant to rule over the rest of nature. & -0.08 & 0.22 & 0.76 & 0.39 \\
\hline 13. The balance of nature is very delicate and easily upset. & 0.67 & 0.07 & 0.00 & 0.39 \\
\hline $\begin{array}{l}\text { 14. Humans will eventually learn enough about how nature } \\
\text { works to be able to control it. }\end{array}$ & 0.05 & 0.48 & 0.36 & 0.23 \\
\hline $\begin{array}{l}\text { 15. If things continue on their present course, we will soon } \\
\text { experience a major ecological catastrophe. }\end{array}$ & 0.77 & -0.02 & -0.16 & 0.56 \\
\hline Unrotated Eigenvalues & 4.09 & 2.67 & 1.06 & \\
\hline Unrotated \% of Variance & 27.23 & 17.77 & 7.06 & \\
\hline
\end{tabular}

Note: Factor loadings greater than 0.30 are in bold type. ${ }^{*}$ Corrected item-total correlations: values lower than 0.30 are in bold type. $\mathrm{N}=3607$. Rotation method: Varimax with Kaiser normalization.

Table 4. Comparative factor structure for the NEP: Dunlap et al. versus SETss at pretest.

\begin{tabular}{cccc}
\hline Dunlap et al. "Facets" & Item Number & Dunlap et al. Factors & SETss Factor \\
\hline Limits & 1. We are approaching the limit ... & 3 & 1 \\
& 6. The earth has plenty of .. & 2 & 2 \\
11. The earth is like a spaceship ... & 3 & 1 \\
Anti Anthro & 2. Humans have the right to modify ... & 4 & 3 \\
& 7. Plants and animals have ... & 4 & 1 \\
Fragility & 12. Humans were meant to rule ... & 4 & 3 \\
& 3. When humans interfere ... . & 1 & 1 \\
Anti Exempt & 8. The balance of nature is ... & 2 & 1 \\
& 13. The balance of nature is .. delicate ... & 1 & 2 \\
4. Human ingenuity will insure ... & 2 & 1 \\
Eco Crisis & 9. Despite our special abilities ... & 1 & 2 \\
& 14. Humans will eventually ... control ... & 2 & 1 \\
& 5. Humans are severely abusing ... & 1 & 1 \\
& 10. The so-called "ecological crisis" ... & 1 & 1 \\
\hline
\end{tabular}

Note: Columns 1 and 2 are divided into Dunlap et al.'s five "facets" and the questions that pertain to them (for the full wording refer to Table 3). Columns 3 and 4 are color-coded by factor for ease of comparison of Dunlap et al.'s 4 -factor results and the 3 -factor results from this study.

Dunlap et al.'s [9] four factor structure was not supported by reliability analysis results of SETss NEP responses (Table 4). In this sample only three factors emerge. However, three of Dunlap et al.'s "facets" 
loaded in the same manner: Fragility, Anti-exemptionalism and Eco-crisis. Furthermore, at least one item from each facet loads most heavily on the first factor, also in line with Dunlap et al.'s findings. In the remaining "facets", three items in our sample load most heavily onto the first factor rather than those with low eigenvalues, in contrast to Dunlap et al.'s results.

The NEP showed strong, positive correlations with both Biospheric Values $(0.464, p<0.01)$ and Environmental Citizenship (0.468, $p<0.01$; Table 5). A moderate, negative correlation existed between NEP and Egoistic Values $(0.297, p<0.01)$. The Connectedness to Nature scale was moderately correlated with the NEP $(0.416, p<0.01, \mathrm{n}=568)$ and is omitted from Table 5 as no correlations could be calculated with other variables as they were not assessed concurrently in any years.

Table 5. Pearson correlations for NEP and values at pretest and posttest.

\begin{tabular}{|c|c|c|c|c|c|}
\hline & NEP & Altruistic & Biospheric & Egoistic & Environmental Citizenship \\
\hline NEP & $\begin{array}{c}1 \\
(\mathrm{n}=3607)\end{array}$ & $\begin{array}{l}0.211^{* *} \\
(n=616)\end{array}$ & $\begin{array}{l}0.485 * * \\
(n=614)\end{array}$ & $\begin{array}{l}-0.250 * * \\
(n=614)\end{array}$ & $\begin{array}{c}416^{* *} \\
(n=3079)\end{array}$ \\
\hline Altruistic & $\begin{array}{l}0.190^{* *} \\
(\mathrm{n}=616)\end{array}$ & $\begin{array}{c}1 \\
(\mathrm{n}=1079)\end{array}$ & $\begin{array}{c}\mathbf{0 . 4 4 2} * * \\
(n=1076)\end{array}$ & $\begin{array}{c}\mathbf{0 . 0 2 6} \\
(n=1075)\end{array}$ & $\begin{array}{l}0.219 * * \\
(n=600)\end{array}$ \\
\hline Biospheric & $\begin{array}{l}0.464^{* *} \\
(\mathrm{n}=613)\end{array}$ & $\begin{array}{c}0.367^{* *} \\
(\mathrm{n}=1066)\end{array}$ & $\begin{array}{c}1 \\
(\mathrm{n}=1079)\end{array}$ & $\begin{array}{c}-0.063 * \\
(n=1076)\end{array}$ & $\begin{array}{l}\mathbf{0 . 4 5 4} * * \\
(n=599)\end{array}$ \\
\hline Egoistic & $\begin{array}{l}-0.297^{* *} \\
(\mathrm{n}=616)\end{array}$ & $\begin{array}{c}0.002 \\
(n=1068)\end{array}$ & $\begin{array}{l}-0.082^{* *} \\
(\mathrm{n}=1066)\end{array}$ & $\begin{array}{c}1 \\
(\mathrm{n}=1080)\end{array}$ & $\begin{array}{l}-\mathbf{0 . 1 1 9} * * \\
(n=599)\end{array}$ \\
\hline $\begin{array}{l}\text { Environmental } \\
\text { Citizenship }\end{array}$ & $\begin{array}{c}0.468 * * \\
(\mathrm{n}=3113)\end{array}$ & $\begin{array}{l}0.180^{* *} \\
(\mathrm{n}=601)\end{array}$ & $\begin{array}{l}0.549^{* *} \\
(\mathrm{n}=600)\end{array}$ & $\begin{array}{l}-0.135^{* *} \\
(\mathrm{n}=600)\end{array}$ & $\begin{array}{c}1 \\
(\mathrm{n}=4036)\end{array}$ \\
\hline
\end{tabular}

The return of moderate correlations in the expected direction to other values-based variables in accordance with the knowledgebase supports the assertion that the NEP is functioning as intended and can discriminate changes in values/beliefs underlying the scale within the sample. Given the large sample size, the fact that the factor structure revealed by exploratory principal components analysis is similar to Dunlap et al.'s [9] results and that the two items with concerning corrected item-total correlations are not overly influential on coefficient alpha, the authors proceed as Dunlap et al. [9] recommend under such circumstances and accept the scale as unidimensional.

\subsection{Hypothesis 1: Demographic Relationships to NEP at Pretest}

Within the entire metadataset, stepwise regression yielded a model with Political Orientation $(\beta=-0.61, \mathrm{SE}=0.043)$, Gender $(\beta=0.35, \mathrm{SE}=0.047)$ and Business Focus $(\beta=-0.14, \mathrm{SE}=0.054)$ as important contributors to variation in NEP z-scores at pretest $(\mathrm{n}=2001, \mathrm{~F}=103.56, p<0.001$; Table 6$)$. Demographic factors were found to have a significant association with NEP score at pretest, supporting H1 overall:

a. Identifying as female was associated with higher NEP scores at pretest.

b. Liberal political beliefs were associated with higher NEP scores at pretest (and explained the most variation in NEP scores at pretest).

c. Business majors were associated with lower NEP scores at pretest.

d. Class standing was not significantly associated with NEP scores at pretest.

e. Number of sustainability-related courses was not significantly associated with NEP scores at pretest. 
Table 6. Stepwise regression of demographic factors on NEP z-score at pretest A (entire metadaset; $\mathrm{n}=2001)$.

\begin{tabular}{ccccccc}
\hline Model \#. Variable Added & Cumulative $\mathbf{R}^{*}$ & $\mathbf{R}^{\mathbf{2}}$ Change & F Change & df1 & df2 & Sig. F Change \\
\hline 1. Political Orientation & 0.320 & 0.102 & 227.628 & 1 & 1999 & 0.000 \\
2. Gender & 0.363 & 0.029 & 67.432 & 1 & 1998 & 0.000 \\
3. Business Focus & 0.367 & 0.003 & 7.117 & 1 & 1997 & 0.008 \\
\hline
\end{tabular}

Note: Independent variables entered: Gender, Political Orientation, Business Focus, Class Standing, Number of Human-Ecology Courses. * $\mathrm{R}$ is cumulative in this column as model \# increases.

Within the subset of SETsS subjects, stepwise regression yielded a model that included Political Orientation $(\beta=-0.65, \mathrm{SE}=0.05)$ and $\operatorname{Gender}(\beta=0.41, \mathrm{SE}=0.05)$ as significant contributors to variation in NEP z-scores at Pretest $(\mathrm{n}=1446, \mathrm{~m}=52.19, \mathrm{~d}=6.839, \mathrm{~F}=126.83, p<0.001)$. Variable selection results are presented in Table 7 . Demographic factors have a significant association with NEP score at pretest within SETss students, supporting H1. Identifying as female is associated with higher NEP scores at pretest, while leaning to the political right is associated with lower NEP scores at pretest. Of these, Political Orientation contributed the most to explaining the variation in NEP scores for SETss students.

Table 7. Stepwise regression of demographic factors on NEP z-score at pretest B (Sustainable Educational Travel group; $\mathrm{n}=1446)$.

\begin{tabular}{ccccccc}
\hline Model \#. Variable Added & Cumulative $\mathbf{R}^{*}$ & $\mathbf{R}^{\mathbf{2}}$ Change & F Change & df1 & df2 & Sig. F Change \\
\hline 1. Political Orientation & 0.338 & 0.114 & 186.447 & 1 & 1444 & 0.000 \\
2. Gender & 0.387 & 0.035 & 59.641 & 1 & 1443 & 0.000 \\
\hline
\end{tabular}

Note: Independent variables entered: Gender, Political Orientation, Business Focus, Class Standing, Number of Human-Ecology Courses. ${ }^{*} \mathrm{R}$ is cumulative in this column as model \# increases.

\subsection{Hypothesis 2: Sustainable Educational Travel Versus Other Programs}

Repeated measures ANOVA results showed a significant, but small, interaction for Time and Treatment $(\mathrm{n}=1638, \mathrm{~F}=37.65, \mathrm{df}=1, p<0.001$, partial $\omega 2=0.01)$ and a significant, but small, effect for Treatment $(\mathrm{F}=54.46, \mathrm{df}=1, p<0.001$, partial $\omega 2=0.02)$. SETss students' NEP scores rose from pretest $(\mathrm{m}=52.69, \mathrm{SE}=0.17)$ to posttest $(\mathrm{m}=53.67, \mathrm{SE}=0.19)$ whereas $\mathrm{OP}$ students showed no significant change in mean NEP score from pretest $(\mathrm{m}=51.20, \mathrm{SE}=0.23)$ to posttest $(\mathrm{m}=51.02, \mathrm{SE}=0.25$; Figure 2$)$.

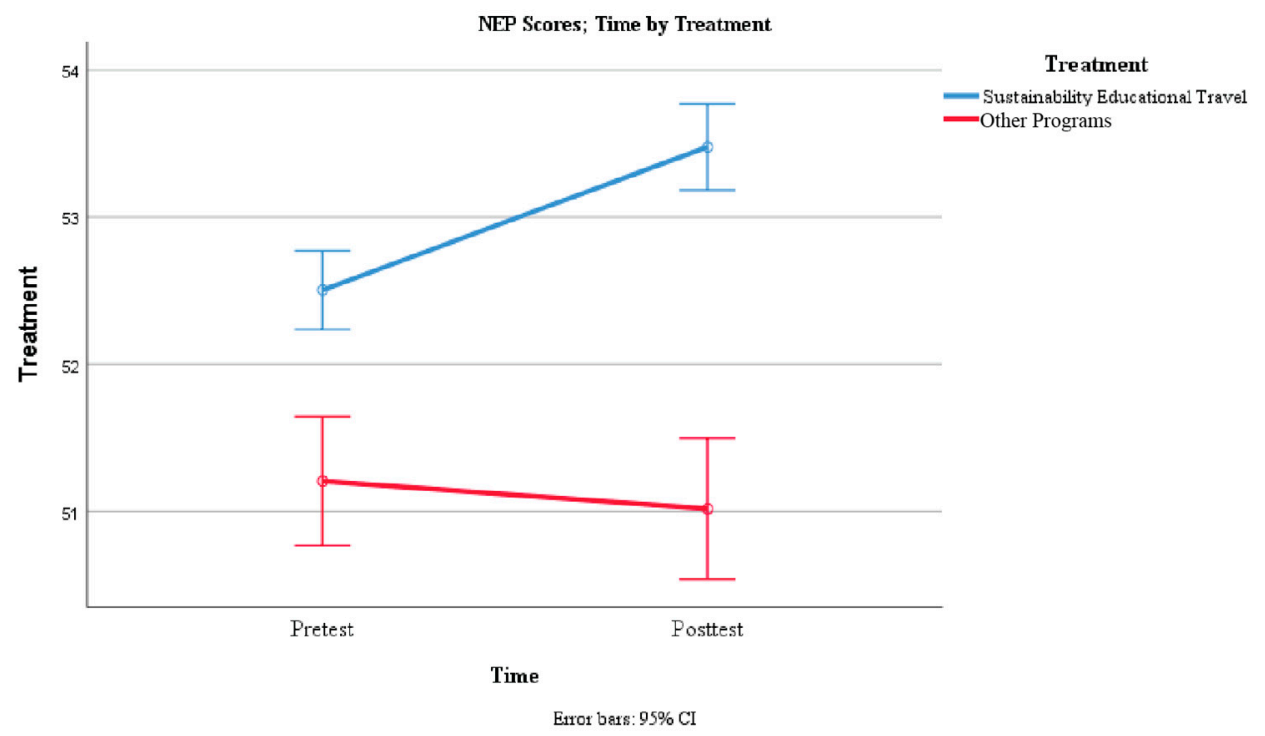

Figure 2. NEP scores over Time by Treatment. 
The paired t-test revealed a significant difference between pretest and posttest mean NEP scores (pretest $=52.52, \mathrm{sd}=6.78$; posttest $=53.47, \mathrm{sd}=7.434)$ for SETss students $(\mathrm{n}=2501, \mathrm{t}=-9.53, \mathrm{df}=250$, $p<0.001$ ). At the $95 \%$ confidence level, there is support for $\mathrm{H} 2$ that, on average, NEP scores at posttest are higher than at prettest in Sustainable Educational Travel programs.

\subsection{Hypothesis 3: Demographic Predictors of Response to Treatment in SETsS Students}

Stepwise regression of demographic variables returned a model with Gender $(\beta=0.10, \mathrm{SE}=0.05)$ as the only significant predictor of change in NEP (as z-scores) pretest to posttest $(R=0.06, F=5.027$, $p<0.05$ ), supporting H3. Being female is weakly associated with higher change in NEP scores from pretest to posttest.

Linear regression showed a significant inverse relationship between change in NEP (as z-scores) pretest to posttest and NEP $\mathrm{z}$-scores at pretest $(\mathrm{n}=2501, \mathrm{~F}=8.24, p<0.01)$. Students in SETss programs who scored lower on the NEP scale at pretest were more likely to show greater gains in NEP score from pretest to posttest than those with higher NEP scores at pretest (Figure 3).

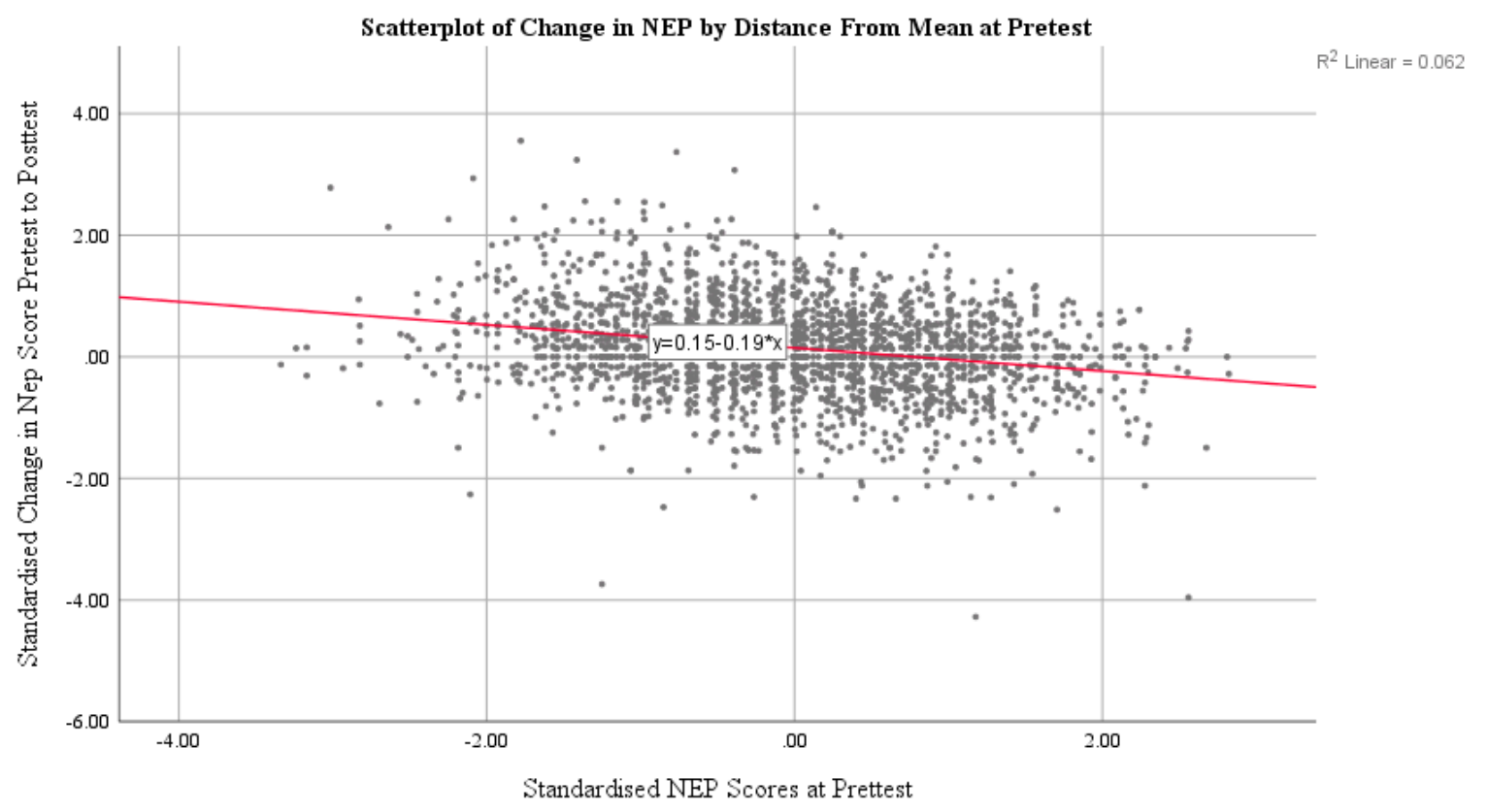

Figure 3. Scatterplot of change in NEP by distance from mean at pretest in Sustainable Educational Travel students. Note: change scores and pretest scores are z-scores standardized by year.

Inclusion of NEP z-score at pretest as an independent variable into a stepwise regression with demographic variables yielded a model that retained it as the most significant variable $(\beta=-0.21$, $\mathrm{SE}=0.02$ ) in accounting for variation in change in NEP (as z-scores) pretest to posttest. The model $(\mathrm{n}=1389, \mathrm{~F}=31.95, p<0.001$; Table 8$)$ also retained Gender $(\beta=0.19, \mathrm{SE}=0.04)$ and Political Orientation $(\beta=-0.09, \mathrm{SE}=0.04)$ as significant explanatory variables. Being female is associated with greater gains in change in NEP (as z-scores) pretest to posttest, as is leaning towards the political left. 
Table 8. Stepwise regression of demographic factors and NEP z-scores at pretest on change in NEP (as z-scores) pretest to posttest $(n=1389)$.

\begin{tabular}{ccccccc}
\hline Model \#. Added Variable & Cumulative $\mathbf{R}^{*}$ & $\mathbf{R}^{\mathbf{2}}$ Change & F Change & df1 & df2 & Sig. F Change \\
\hline 1. Standardised Distance & 0.222 & 0.049 & 72.133 & 1 & 1387 & 0.000 \\
from Mean NEP at Pretest & 0.249 & 0.013 & 18.649 & 1 & 1386 & 0.000 \\
2. Gender & 0.254 & 0.003 & 3.959 & 1 & 1385 & 0.047 \\
\hline 3. Political Orientation & &
\end{tabular}

Note: Independent variables entered: Gender, Political Orientation, Business Focus, Class Standing, Number of Human-Ecology Courses. ${ }^{*} \mathrm{R}$ is cumulative in this column as model \# increases.

\section{Discussion}

\subsection{Socio-Demographic Predictors of the NEP}

The results of variable selection within the entire metadataset align with Dunlap et al.'s [9] findings on antecedents of the New Ecological Paradigm (NEP), to some degree. Of the three variables in this study that correspond to those used by Dunlap et al. [9], i.e., gender, political orientation and intended occupation (major of study), only the latter two showed the same relationships and were negatively associated with NEP scores at pretest. Results for gender as a predictor of NEP scores at pretest went against Dunlap et al.'s [9] findings and showed a significant positive relationship at pretest.

\subsubsection{Gender}

In contrast to Dunlap et al.'s [9] findings, gender is found to be a significant predictor of NEP. However, this result is in line with other work on environmental attitudes see [23-26,29]. This makes sense in light of Stern et al.'s [29] characterization of an individual's position in the social structure as antecedent to worldview. If a society has significant differences in the position of genders within its structure/s, one expects to see differences in worldview between genders. For example, Zelezny et al. [48] found, compared to males, females are more likely to take account of the needs of others, to have higher levels of socialization and to be more socially responsible. This supports the idea that women can have a different experience of social structure than men, which in turn supports the finding of significant differences in worldview between genders.

\subsubsection{Liberal Political Beliefs}

The positive association between liberal political leaning and higher NEP scores at pretest resonates with results from other studies see [9,23,24]. Returning to Stern et al.'s [29] hierarchy, one's political beliefs can be seen as a set of specific beliefs and attitudes based upon broader beliefs and a worldview derived from an individual's values. Thus, it is not surprising this study finds a relationship between liberal political beliefs and higher NEP scores. For example, those with conservative political beliefs that the "market will fix everything" are less likely to identify with the "limits to growth" facet of the NEP.

Recent work by Ziegler [49] found considerable overlap between political orientation and environmental values (i.e., the NEP) in explaining variation in beliefs and attitudes on climate change. Furthermore, he found significant differences in the interaction of those variables when comparing the United States, Germany and China, suggesting that the relationship between the NEP and political orientation varies between cultures. Again, this reinforces Stern et al.'s [29] assertion that social structures precede values, which precede worldviews (including the NEP), which precede specific beliefs and attitudes (including political orientation).

\subsubsection{Business Majors}

Dunlap et al. [9] found occupational sector to be a significant predictor of NEP. The results of this study show business-related majors to be associated with lower NEP scores at pretest, adding definition 
to this relationship for the college student demographic. The fact that business major was retained as a significant contributor to variation in NEP scores at pretest alongside political orientation for the entire metadataset is of interest. Regardless of political orientation, or gender, college students who choose business majors over other fields of study on average score lower on the NEP than those with other occupations in mind.

One way of contextualizing this is to regard the choice of field of study as a behavioral commitment. From this perspective, it is underpinned by one's values and beliefs (including one's worldview) and should bear some relation to them. Furthermore, one's choice of intended career is a potentially life-changing decision and should reflect an individual's core values more than a decision such as whether to install solar panels on one's roof.

\subsubsection{Class Standing}

Class standing was not found to be a significant predictor of NEP scores. As a proxy for either age, or education level, the variable's range may have been too restrictive (given this sample has few respondents outside undergraduate age range) to return results comparable to Dunlap et al. [9], who found age to have a weak negative association with NEP scores and others who have found age or birth cohort to be predictors of environmentalism [21,22]. However, the result informs us that increments in educational level at this scale do not significantly contribute to variation in NEP scores.

One way of considering this result is from the perspective of self-selection of major of study. Prospective students approaching college education may seek areas of study that resonate with their world view, and/or that of their parents, potentially reducing the likelihood of them encountering educational transformative experiences that may alter, or broaden, that worldview. Selecting courses of study that sit comfortably within one's worldview may reduce the chance of encountering learning experiences capable of causing the cognitive dissonance whose resolution lies at the heart of theories of experiential learning as one progresses through college education.

Comparing the MDS variable selection results with those for the SETss category, we see the Business Focus now absent from the best model identified by stepwise regression to account for variability in NEP score at pretest. This is counterintuitive, given the higher percentage of business school students in the SETss group in comparison to the Other Program (OP) group (22\% versus $18 \%$, respectively).

Again, the most obvious rationale to address the difference is self-selection. Students are actively seeking out study abroad opportunities, of which a large range are on offer. Those that choose Sustainable Educational Travel programs may be predisposed to sustainability concepts or at least accepting of them. They may also be selecting the programs for their travel component, in contrast with studying abroad at a single institution or location. Furthermore, the choice to study abroad, regardless of the mode of study, may be indicative of students looking to broaden their worldviews who may therefore be more likely to alter their worldview to some degree.

With this in mind, a posthoc one-way ANOVA was conducted within business students (as a subset of the metadataset) using NEP pretest z-scores (standardized by year) as the independent variable and SETss/OP as the categorical dependent variable. In SETss students, mean NEP pretest $z$-score was $-0.20(n=399)$ while for OP students it was $-0.54(n=77)$. ANOVA results showed mean NEP pretest z-scores were significantly higher in SETss students than in OP students, supporting the idea that self-selection is at work, at least in the subset of business majors.

\subsubsection{Number of Sustainability-Related Courses}

Model building did not retain the number of sustainability-related courses as a significant predictor of NEP scores at pretest. This is counter intuitive. One would think that as a student is exposed to more sustainability-related courses, their worldview would become more environmentally focused. However, sustainability literacy research has indicated that there may be a threshold effect at work. Horvath et al. [50] found that students who had undertaken fewer than three sustainability-related 
courses were no more knowledgeable about sustainability than students who had undertaken none. Future research on the effect of the number of sustainability courses on student NEP scores is required to understand if such a threshold is at work.

\subsection{The Effect of Sustainable Educational Travel}

The repeated measures ANOVA yielded results consistent with both the literature and theory. Travel-based study abroad programs are known to be efficacious at positively moving environmental measures in comparison to residential study abroad programs and home campus courses [51]. It should be noted that the mean shift of NEP scores pretest to posttest, while significant, was relatively small. This is consistent with the notion that the NEP is measuring values and/or beliefs. According to VBN theory, values are more resistant to change than beliefs, which in turn are more resistant to change than norms $[33,46]$. Furthermore, the difference between mean NEP scores at pretest illustrates the idea of self-selection discussed below in relation to changes in NEP scores in response to treatment.

\subsection{Socio-Demographic Predictors of Change in NEP Scores}

On average, students who were 0.79 standard deviations above mean NEP score at pretest are least likely to demonstrate any change in NEP score at posttest. Students below 0.79 standard deviations above the mean at pretest are likely to increase their score pretest to posttest, while those above 0.79 standard deviations above the mean at pretest are likely to decrease their score pretest to posttest.

Furthermore, the greater the difference between a student's NEP z-score at pretest and 0.79 standard deviations above the mean, the greater the absolute magnitude of change in standardized NEP score is likely to be, pretest to posttest. On average, those that scored lowest on the NEP at pretest had the greatest positive change from pretest to posttest, while those that scored the highest showed the greatest negative change from pretest to posttest.

It is possible that two processes detrimental to results are at work here. First, respondents close to either the lowest or highest possible NEP score at pretest may be subjected to a "ceiling/floor effect" on posttest. For the lowest respondents, there is nowhere to go but up. For the highest, there is nowhere to go but down. However, if all things are equal pretest to posttest, why would they change at all? Second, the observed pattern may be indicative of regression to the mean, whereby unavoidable sources of error in repeated measurements of a stable property yield non-identical results that trend towards the mean [52-54].

However, NEP score variance increases from pretest to posttest (see standard deviations in Table 2), which runs contrary to expectations if regression to the mean is at work. If regression to the mean influences these results, we would expect variance to also decrease from pretest to posttest as more extreme results are moderated back towards the mean. The fact that variance increases from pretest to posttest gives us confidence that what we are seeing is likely to be related to actual processes rather than being a statistical artefact.

Several explanations for this observation resonate. First, students in SETss programs may be increasing or refining their understanding of their own worldview through the experience of contrasting it with cultural others. This may allow them to bring a more informed sense of their own worldview to the scale at posttest, i.e., causal factors have potentially changed between surveys [55]. However, this offers no explanation as to why this experience would differentiate the magnitude or direction of change in evidence here.

Second, self-selection may be at work. Students who select SETss programs may have a predisposition to responding more positively to the programs' contents, which explore pathways to balancing the triple bottom line. It may be a case of preaching to the choir. As before, it is difficult to see why this would differentiate the magnitude or direction of change for subjects at different positions on the scale at pretest.

Third, sustainability as a concept goes further than ecological world view, as conceived during the era that spawned the first iteration of the NEP. Sustainability certainly recognizes the environment 
as a critical component of human well-being now and into the future, but it does not place it above the more anthropocentric concepts of social and economic well-being. It is, therefore, possible that SETss students who weight any of those three elements heavily in one direction or another at pretest, are being exposed to arguments for a more balanced approach. For example, someone with a strong environmental worldview may moderate their perspective if exposed to critical analysis of the triple bottom line concept for the first time. This has the capacity to explain what is observed occurring to change in NEP scores in this study.

Fourth, and related to the previous point, it is possible that other social-psychological factors are in play. SETss programs are termed island programs. Students are guided through unfamiliar physical and cultural landscapes in the knowledge that the safety and familiarity of their own cultural context is only ever as far away as their faculty and cohort. They eat, study, play and travel with each other and their faculty for periods ranging from three weeks to three months. Anecdotally, at least some students form new social coteries with people they did not know prior to the study abroad program.

This potentially intense social experience gives rise to the possibility that students shift their ideas of what is normative while on program and beyond. This concept also has the potential to explain why those at the extreme ends of the NEP scale are most likely to move towards the mean.

\subsection{Limitations}

Some inherent limitations should be noted. First, the inconsistency in the dimensionality of the NEP between samples noted elsewhere in the literature presents itself here. The authors have done their best to alleviate this issue by following Dunlap et al.'s [9] procedures and recommendations in this regard and have presented the results in some detail to contextualize comparison between past and future work with the NEP and this study.

Second, the interactive effect of testing is unknown. For SETss programs, surveying occurs on the first and last day of the programs. Both are auspicious occasions during which students may be more or less excited/trepidatious about the beginning/end of their study abroad experience. If the effect is similar at both pretest and posttest, this point is moot. However, should such an effect be at work its influence would be difficult to ascertain.

Third, the span of time of data collection (2008-2018) was of concern due to the possibility of instructor bias and yearly cohort effects confounding results. Some instructors for SETss programs have been with the program for substantial periods of time while others remain for one or two years only. Accounting for the effect of instructors' abilities, and also for those who get better at teaching the course content through time, is difficult.

The authors see no way of accurately accounting for differences in instructor's abilities within a given year. However, the standardization of change in NEP scores by year is intended to adjust for incremental gains in instructor effectiveness from year to year, while the standardization of NEP scores at pretest is intended to adjust for any yearly cohort effect. Furthermore, although the seasonal context of the field locations is variable to some degree from program to program, the course content comes from a textbook specifically written for the course by the program director, and the in-country field guides have remained remarkably stable through time. This gives the authors some confidence that instructor and cohort effects have been significantly reduced.

\section{Conclusions}

\subsection{Socio-Demographic Predictors of the NEP}

The retention of gender as a significant predictor of variation in NEP scores, in contrast to Dunlap et al.'s [9] findings, reiterates the need to validate the NEP for each population within which it is deployed. This is further reinforced by the differences in factor structure of the NEP between this study and the aforementioned work. The NEP's dimensionality does indeed appear to be sample dependent. 


\subsection{The Effect of Sustainable Educational Travel}

The small, but significant, positive effect of sustainable educational travel on NEP scores across the duration of a program is no surprise. Of more interest is which processes, within sustainable educational travel, are responsible for the effect. This is a difficult area to investigate experimentally within the educational context of this study. However, examination of the interaction between socio-demographic antecedents of changes in NEP scores may provide some direction and are discussed below.

\subsection{Socio-Demographic Predictors of Change in NEP Scores}

These results suggest that within programs with a demonstrated ability to influence environmental world view, albeit marginally, the predictors of environmental worldview at the commencement of a program are not necessarily the predictors of susceptibility to change. The fact that political orientation was a significant predictor of NEP score at pretest but was not a significant predictor of change in NEP score should give educators hope. That difference suggests that higher education has the ability to overcome at least some of the biases students bring with them to the educational discourse and that SETss programs are effective at doing so.

Educators wishing to leverage this effect may wish to consider whether the pedagogies upon which SETss programs are based can be incorporated into their curricula, i.e., experiential learning theory (ELT), transformational learning theory (TLT), situational learning theory (SLT) and critical cultural pedagogy (CCP). To that end, further studies endeavoring to narrow down what aspects of SETss most contribute to such change would be of interest. Of course, it would be beneficial to know whether particular components of SETss programs are more effective at generating the observed effect than others. Within the syllabi of the SETss programs used for this study, one component stands out from others as exemplifying the tenets of ELT, TLT, SLT and CCP experiences; the socio-scientific issue (SSI).

SSIs are used to encourage reflection on the knowledge and application of knowledge surrounding a given issue in society [56]. In SETss programs, SSIs are deployed in programs visiting Australia and New Zealand to focus student learning on contemporary "wicked" problems, which have multiple stakeholders, different outcomes at different scales and no single solution. Students are assigned stakeholder or decision-maker roles and must research and present or conduct their case per that role. Research through interaction with local stakeholders is encouraged. Students playing decision-maker roles deliberate after stakeholder presentations and come to a decision, which is debated in character and then debriefed out of character.

As such, SSIs utilize reflection as a core process in the construction of meaning in line with ELT and TLT. Furthermore, through being physically present in the socio-political context of the issue at hand, the immersive aspect of SLT and the balance of power focus of CCP are invoked. Should other educators wish to explore the potential of SETss pedagogies in their own practice, we recommend SSIs as promising starting point.

However, in order to recommend specific practices for educators to deploy in pursuit of such goals more resolution on the agents of change is required. Testing the effect of SSIs on worldviews appears to be the lowest hanging fruit. The authors urge others with the opportunity to do so to contribute to the discourse on the social-psychological predictors of beliefs and their malleability in the sustainability education setting.

Author Contributions: Conceptualization, M.T. and S.L.; methodology, M.T.; validation, S.L. and A.L.; formal analysis, S.L. and A.L.; investigation, S.L.; data curation, S.L. and A.L.; writing-original draft preparation, S.L.; writing-review and editing, S.L., A.L., M.T., and D.R. All authors have read and agreed to the published version of the manuscript.

Funding: This research received no external funding.

Conflicts of Interest: The authors declare no conflict of interest. 


\section{References}

1. Institute of International Education. Open Doors Press Release. 2019. Available online: https://www.iie.org/Why-IIE/Announcements/2019/11/Number-of-International-Students-in-the-UnitedStates-Hits-All-Time-High (accessed on 18 January 2019).

2. Bell, H.L.; Gibson, H.J.; Tarrant, M.A.; Perry, L.G.; Stoner, L. Transformational learning through study abroad: US students' reflections on learning about sustainability in the South Pacific. Leis. Stud. 2014, 35, 389-405. [CrossRef]

3. Paige, R.M.; Fry, G.W.; Stallman, E.M.; Josić, J.; Jon, J. Study abroad for global engagement: The long-term impact of mobility experiences. Intercult. Educ. 2009, 20, S29-S44. [CrossRef]

4. Tarrant, M.A.; Stoner, L.; Borrie, W.T.; Kyle, G.; Moore, R.L.; Moore, A. Educational Travel and Global Citizenship. J. Leis. Res. 2011, 43, 403-426. [CrossRef]

5. Tarrant, M.A. A Conceptual Framework for Exploring the Role of Studies Abroad in Nurturing Global Citizenship. J. Stud. Int. Educ. 2009, 14, 433-451. [CrossRef]

6. Dunlap, R.E. The New Environmental Paradigm Scale: From Marginality to Worldwide Use. J. Environ. Educ. 2008, 40, 3-18. [CrossRef]

7. Azjen, I.; Fishbein, M. The predication of behavior from attitudinal and normative variables. J. Exp. Soc. Psychol. 1970, 6, 466-487.

8. Stern, P.C.; Dietz, T.; Guagnano, G.A. The New Ecological Paradigm in Social-Psychological Context. Environ. Behav. 1995, 27, 723-743. [CrossRef]

9. Dunlap, R.E.; Van Liere, K.D.; Mertig, A.G.; Jones, R.E. New Trends in Measuring Environmental Attitudes: Measuring Endorsement of the New Ecological Paradigm: A Revised NEP Scale. J. Soc. Issues 2000, 56, 425-442. [CrossRef]

10. Dunlap, R.E.; Van Liere, K.D. The “New Environmental Paradigm". J. Environ. Educ. 1978, 9, 10-19. [CrossRef]

11. Anderson, M. New Ecological Paradigm (NEP) Scale. In The Berkshire Encyclopedia of Sustainability; Anderson, R., Ed.; Berkshire Publishing: Great Barrington, MA, USA; Volume 6, pp. 260-262.

12. Gorsuch, R.L.; Rokeach, M. Beliefs, Attitudes, and Values. Am. Sociol. Rev. 1969, 34, 267. [CrossRef]

13. Google LLC. Google Scholar. Available online: https://scholar.google.co.nz/scholar?hl=en\&as_sdt=0\%2C5\& $\mathrm{q}=\mathrm{New}+$ ecological+paradigm\&btnG= (accessed on 9 February 2019).

14. Hawcroft, L.J.; Milfont, T.L. The use (and abuse) of the new environmental paradigm scale over the last 30 years: A meta-analysis. J. Environ. Psychol. 2010, 30, 143-158. [CrossRef]

15. LaLonde, R.; Jackson, E.L. The New Environmental Paradigm Scale: Has It Outlived Its Usefulness? J. Environ. Educ. 2002, 33, 28-36. [CrossRef]

16. Lundmark, C. The new ecological paradigm revisited: Anchoring the NEP scale in environmental ethics. Environ. Educ. Res. 2007, 13, 329-347. [CrossRef]

17. Messick, S. Validity of Psychological Assessment. Am. Psychol. 1995, 50, 741-749. [CrossRef]

18. Amburgey, J.W.; Thoman, D.B. Dimensionality of the New Ecological Paradigm. Environ. Behav. 2011, 44, 235-256. [CrossRef]

19. Xiao, C.; Buhrmann, J. The Structure and Coherence of the New Environmental Paradigm: Reconceptualizing the Dimensionality Debate. Hum. Ecol. Rev. 2017, 23, 179-198. [CrossRef]

20. Engelhard, G. Invariant Measurement; Routledge: New York, NY, USA, 2013.

21. Jones, R.E.; Dunlap, R.E. The Social Bases of Environmental Concern: Have They Changed Over Time? Rural Sociol. 2010, 57, 28-47. [CrossRef]

22. Van Liere, K.D.; Dunlap, R.E. The Social Bases of Environmental Concern: A Review of Hypotheses, Explanations and Empirical Evidence. Public Opin. Q. 1980, 44, 181. [CrossRef]

23. Johnson, C.Y.; Bowker, J.M.; Cordell, H.K. Ethnic Variation in Enviromental Belief and Behavior: An Examination of the New Ecological Paradigm in a Social Psychological Context. Environ. Behav. 2006, 36, 157-186. [CrossRef]

24. Casey, P.J.; Scott, K. Environmental concern and behaviour in an Australian sample within an ecocentric-Anthropocentric framework. Aust. J. Psychol. 2006, 58, 57-67. [CrossRef]

25. Rexeisen, R. The Impact of Study Abroad on the Development of Pro-environmental Attitudes. Int. J. Sust. Educ. 2014, 9, 7-19. [CrossRef] 
26. Rexeisen, R.J.; Al-Khatib, J. Assurance of Learning and Study Abroad: A Case Study. J. Teach. Int. Bus. 2009, 20, 192-207. [CrossRef]

27. Kalof, L.; Dietz, T.; Guagnano, G.; Stern, P.C. Race, Gender and Environmentalism: The Atypical Values and Beliefs of White Men. Race Gend. Cl. Conf. Others 2000, 9, 112-130. [CrossRef]

28. Rideout, B.E.; Hushen, K.; McGinty, D.; Perkins, S.; Tate, J. Endorsement of the New Ecological Paradigm in Systematic and E-mail Samples of College Students. J. Environ. Educ. 2005, 36, 15-23. [CrossRef]

29. Stern, P.C.; Dietz, T.; Kalof, L. Value Orientations, Gender, and Environmental Concern. Environ. Behav. 1993, 25, 322-348. [CrossRef]

30. Schwartz, S.H. Normative Influences on Altruism. Adv. Exp. Soc. Psychol. 1977, 10, 221-279. [CrossRef]

31. Ajzen, I. The Theory of Planned Behavior. Organ. Behav. Hum. Decis. Process. 1991, 50, 179-211. [CrossRef]

32. Kaiser, F.G.; Hübner, G.; Bogner, F.X. Contrasting the Theory of Planned Behavior With the Value-Belief-Norm Model in Explaining Conservation Behavior. J. Appl. Soc. Psychol. 2005, 35, 2150-2170. [CrossRef]

33. Stern, P.C.; Kalof, L.; Dietz, T.; Guagnano, G.A. Values, Beliefs, and Proenvironmental Action: Attitude Formation Toward Emergent Attitude Objects. J. Appl. Soc. Psychol. 1995, 25, 1611-1636. [CrossRef]

34. Wynveen, C.J.; Kyle, G.T.; Tarrant, M.A. Study Abroad Experiences and Global Citizenship. J. Stud. Int. Educ. 2011, 16, 334-352. [CrossRef]

35. De Groot, J.I.M.; Steg, L. Value Orientations to Explain Beliefs Related to Environmental Significant Behavior. Environ. Behav. 2007, 40, 330-354. [CrossRef]

36. Liu, X.; Zou, Y.; Wu, J. Factors Influencing Public-Sphere Pro-Environmental Behavior among Mongolian College Students: A Test of Value-Belief-Norm Theory. Sustainability 2018, 10, 1384. [CrossRef]

37. Kolb, D.A. Experiential Learning: Experience as the Source of Learning and Development; Prentice Hall: Upper Saddle River, NJ, USA, 1984.

38. Mezirow, J. Fostering Critical Reflection in Adulthood; Jossey-Bass: San Francisco, CA, USA, 1990.

39. Stone, G.A.; Duffy, L.N. Transformative Learning Theory: A Systematic Review of Travel and Tourism Scholarship. J. Teach. Travel Tour. 2015, 15, 204-224. [CrossRef]

40. Hanson, L. Global Citizenship, Global Health, and the Internationalization of Curriculum. J. Stud. Int. Educ. 2008, 14, 70-88. [CrossRef]

41. Brown, J.S.; Collins, A.; Duguid, P. Situated Cognition and the Culture of Learning. Situat. Cognit. Cult. Learn. 1988, 18, 32-42. [CrossRef]

42. Fenwick, T.J. Experiential Learning: A Theoretical Critique from Five Perspectives. 2001. Available online: https://files.eric.ed.gov/fulltext/ED454418.pdf (accessed on 18 January 2019).

43. Fenwick, T.J. Expanding Conceptions of Experiential Learning: A Review of the Five Contemporary Perspectives on Cognition. Adult Educ. Q. 2000, 50, 243-272. [CrossRef]

44. Giroux, H.A.; McLaren, P.L. Introduction: Schooling, Cultural Politics and the Struggle for Democracy. In Critical Pedagogy, the State, and Cultural Struggle; Giroux, H.A., McLaren, P., Eds.; State University of New York: Albany, NY, USA, 1989.

45. Harraway, J.; Broughton-Ansin, F.; Deaker, L.; Jowett, T.; Shephard, K. Exploring the Use of the Revised New Ecological Paradigm Scale (NEP) to Monitor the Development of Students' Ecological Worldviews. J. Environ. Educ. 2012, 43, 177-191. [CrossRef]

46. Quinn, J.A. Human Ecology and Interactional Ecology. Am. Sociol. Rev. 1940, 5, 713. [CrossRef]

47. IBM Corp. Released 2017. IBM SPSS Statistics for Windows; Version 25; IBM Corp.: Armonk, NY, USA.

48. Zelezny, L.C.; Chua, P.-P.; Aldrich, C. Elaborating on Gender Differences in Environmentalism. J. Soc. Issues 2000, 56, 443-457. [CrossRef]

49. Ziegler, A. Political orientation, environmental values, and climate change beliefs and attitudes: An empirical cross country analysis. Energy Econ. 2017, 63, 144-153. [CrossRef]

50. Horvath, N.; Steward, M.; Shea, M. Toward Instruments of Assessing Sustainability Knowledge: Assessment Development, Process, and Results From a Pilot Survey at the University of Maryland. J. Sust. Educ. 2013, 5, 311-320.

51. Landon, A.C.; Woosnam, K.M.; Keith, S.J.; Tarrant, M.A.; Rubin, D.L.; Ling, S.T. Understanding and modifying beliefs about climate change through educational travel. J. Sust. Tour. 2019, 27, 292-307. [CrossRef]

52. Agresti, A.; Finlay, B. Statistical Methods for the Social Sciences, 4th ed.; Pearson Prentice Hall: Upper Saddle River, NY, USA, 2009. 
53. Seel, N.M.; Buri, J.R.; Gunty, A.; Dukas, R.; Even, R.; Scheuer, O.; McLaren, B.M.; Okan, Z.; Everhart, D.E.; Schmidt-Kassow, M.; et al. Experimental and Quasi-Experimental Designs for Research on Learning. In Encyclopedia of the Sciences of Learning; Springer Science and Business Media LLC: New York, NY, USA, 2012; pp. 1223-1229.

54. Schwarz, W.; Reike, D. Regression away from the mean: Theory and examples. Br. J. Math. Stat. Psychol. 2017, 71, 186-203. [CrossRef] [PubMed]

55. Nesselroade, J.R.; Stigler, S.M.; Baltes, P.B. Regression toward the mean and the study of change. Psychol. Bull. 1980, 88, 622-637. [CrossRef]

56. Ratcliffe, M.; Grace, M. Science Education for Citizenship: Teaching Socio-Scientific Issues; Open University Press: Maidenhead, UK, 2003.

(C) 2020 by the authors. Licensee MDPI, Basel, Switzerland. This article is an open access article distributed under the terms and conditions of the Creative Commons Attribution (CC BY) license (http://creativecommons.org/licenses/by/4.0/). 